\title{
Multiple cardiac rhabdomyomas in a newborn infant- a case report
}

\author{
Pawan Kumar Sulaniya (MD), R.K. Gupta (MD), Chandrakanta Sulaniya (MS) \\ Department of Pediatric Medicine, S.M.S. Medical College, Jaipur, Rajasthan.
}

\begin{abstract}
Cardiac tumours in the paediatric age group are extremely rare, occurring approximately 1 in 100,000 live births. Rhabdomyomas are the most common type of cardiac tumours. Approximately $70-95 \%$ of rhabdomyomas are associated with tuberous sclerosis. We are reporting a rare case of term neonate, with antenatally diagnosed cardiac tumour. Finally diagnosed as tuberous sclerosis with secondary epilepsy with large multiple cardiac rhabdomyomas. Child is now 2 years old, under follow-up without any cardiac manifestations and rhabdomyomas are regressing on repeat echocardiograms. Only few such cases are reported in literature so far and none from Rajasthan.
\end{abstract}

Key Words: rhabdomyomas, cardiac tumours, tuberous sclerosis

\section{Introduction:}

Cardiac tumours in the paediatric age group are extremely rare occurring approximately 1 in 100,000 live births ${ }^{(1)}$. More than $90 \%$ primary cardiac tumours are benign. Rhabdomyomas are the most common type of cardiac tumours ${ }^{(2,3)}$. Approximately $70-95 \%$ of rhabdomyomas are associated with tuberous sclerosis ${ }^{(2)}$. Babies born with large cardiac rhabdomyomas usually succumb to death within a week or two in early neonatal period. After thorough search of literature, we could found only few case reports of neonatal cardiac rhabdomyomas. We are reporting a case of term neonate, with antenatally diagnosed multiple cardiac rhabdomyomas with tuberous sclerosis, without any cardiac manifestations and growing well till date ( 2 years).

\section{Case report:}

A 26 years old primigravida delivered a full-term male baby through normal delivery. Baby cried immediately and his APGAR score at birth and 5 minutes was normal. Baby was admitted to special care neonatal unit with complaints of peripheral cyanosis with grunting. On examination his vitals were heart rate $156 / \mathrm{M}$, respiratory rate $64 / \mathrm{M}, \mathrm{SPO}_{2} 82 \%$, temperature $36^{\circ} \mathrm{C}$. On examination, two ash leaf spots were noted, one over the right flanks $(19 \mathrm{~mm} \times 8 \mathrm{~mm})$ and second was in left inguinal region $(8 \mathrm{~mm} \times 6 \mathrm{~mm}){ }^{(\mathrm{fig}-1)}$. Systemic examination revealed grade III pan-systolic murmur best heard over lower left sternal border \& mitral area. Liver was palpable $1 \mathrm{~cm}$ below costal margin in mid-clavicular line with soft consistency. Hypothermia, grunting and peripheral cyanosis were recovered by temperature maintenance and oxygen therapy within 3-4 hours. After primary stabilization baby remained asymptomatic throughout the duration of hospital stay.

Lab investigations showed a normal blood count and biochemistry, arterial blood gases were within normal limits and CRP was $5.4 \mathrm{mg} / \mathrm{l}$. Chest X-ray showed cardiomegaly with cardiothoracic ratio of $72 \%$ with oligaemic lung fields.

Antenatal sonogram showed $36 \times 25.9 \mathrm{~mm}$ sized homogenous echogenic mass seen in intracardiac location on atria with no appreciable vasculature, likely rhabdomyoma. Post natal 2D-echocardiogram showed multiple tumors like masses seen in both ventricular cavities, largest in upper part of interventricular septum $(33.6 \times 22.6 \mathrm{~mm})$ obstructing right ventricular outflow tract, with ostium secondum ASD $(3.7 \mathrm{~mm})$ and PDA $(3.9 \mathrm{~mm})$, both of them with left to right shunt ${ }^{(\mathrm{fig}-2)}$. Sub-vulval pulmonary stenosis with pressure gradient of $30.8 \mathrm{~mm}$ of $\mathrm{Hg}$ was also noted.

Ultra sonography brain and whole abdomen were normal. CT head revealed few subependymal hemartomas along ventricular surface of caudate nucleus seen. Few subependymal nodules of size 1-12 mm seen were protruding into adjacent lateral ventricle isodense to white matter. Few cortical and subcortical tubers seen in left lateral high parietal region. All over findings were suggestive of tuberous sclerosis ${ }^{(\mathrm{fig}-3)}$.

This newborn was a product of non-consanguineous marriage, antenatal history was insignificant and Family history and examination of family members was negative for tuberous sclerosis. Baby was discharged on day 7.

Now child is two year old. He developed secondary epilepsy due to tuberous sclerosis at three months of age. His seizures are well controlled on phenytoin. Repeat echocardiogram shows regression of rhabdomyomas and no obstruction to RVOT. At present child does not having any complications related to rhabdomyoma. 


\section{Discussion:}

Cardiac tumours occur very rarely in paediatric patients ${ }^{(3,4,)}$. They may result in serious hemodynamic or electro physiologic abnormalities depending on tumour type and location. The vast majority of tumours originating from the heart are benign. Rhabdomyomas are the most common pediatric cardiac tumours and are associated with tuberous sclerosis in $70-95 \%$ of cases. Rhabdomyomas may occur at any age, from foetal life through late adolescence. They are often multiple, can occur in any cardiac chamber, and originate within the myocardium extending, often, into the atrial or ventricular cavities. Depending on their location and size, they can result in inflow or outflow obstruction leading to cyanosis or cardiac failure. Atrial and ventricular arrhythmias have been reported with rhabdomyomas ${ }^{(1,2,3)}$. Cardiac rhabdomyomas are one of the common presentations of tuberous sclerosis in the neonatal period. Some of the neonates also have skin lesions. The most common skin manifestation of tuberous sclerosis in neonates is the "ash leaf spot," a depigmented macule that may be visible only when illuminated with ultraviolet light ${ }^{(5)}$.

Diagnosis of cardiac rhabdomyoma is done by echocardiography and confirmed by histology. Confirmation of radiological diagnosis by means of biopsy may not be necessary if characteristic features of tuberous sclerosis are present ${ }^{(1,5)}$. Infact, fetal cardiac rhabdomyomas have been used as a marker for prenatal detection of tuberous sclerosis ${ }^{(9)}$.

Echocardiography and Doppler studies also determine the presence, extent and location of the tumor. These studies also determine the hemodynamic significance of the lesion. Their importance in differential diagnosis is also proven. Multiple, interventricular tumors in infants and children most likely are rhabdomyomas. A solitary tumour of varying size arising from the ventricular wall or septum is likely to be fibroma. Left atrial tumors, especially when pedunculated, are usually myxomas. An intracardiac tumor arising near the great arteries most likely is a teratoma. Pericardial effusion suggest a secondary malignant tumor ${ }^{(1,5)}$.

The natural history of cardiac rhabdomyomas in infants and children has been well studied ${ }^{(9)}$. All the studies have shown that these tumors have a propensity for spontaneous regression. Younger the age at diagnosis, higher the chance for spontaneous regression, complete regression being more common in the first 4 years of life ${ }^{(1,8)}$. This has important implications for therapy. Surgical intervention is indicated only in the event of hemodynamic compromise or intractable arrhythmias ${ }^{(1,3)}$.

\section{Conclusion}

Cardiac rhabdomyomas incidences are rare but one of the common presentations of tuberous sclerosis in the neonatal period. These tumours have a propensity for spontaneous regression but sometimes Large multiple cardiac rhabdomyomas may result in serious hemodynamic or electro physiologic abnormalities depending on tumour type and location. In this case it was large enough to cause outflow tract obstruction but on follow-up it is regressing.

\section{References:}

[1]. Park M.K., editor, Cardiac tumors. In: Pediatric cardiology for practitioners. $5^{\text {th }}$ Edition. Philadelphia: Mosby Elsevier, 2008: $402-$ Park

[2]. Spicer R, Ware S. Tumors of the Heart. In: Kliegman R.M., Stanton B.F., Geme J.W.S., Schor N.F., Beherman R.E., editors. Nelson's textbook of pediatrics. $19^{\text {th }}$ edition. Philadelphia: Saunders Elsevier, 2012:1637

[3]. Aggarwal M, Sachan R, Arya S, and Chellani H. Cardiac rhabdomyoma-a case report. Journal of Tropical Pediatrics, 2010, 56:5:345-347

[4]. Ibrahima C.P.H., Thakkera P., Millerb P.A., Barron D. Cardiac rhabdomyoma presenting as left ventricular outflow tract obstruction in a neonate. Interactive cardiovascular and thoracic surgery 2003; 2:572-574

[5]. Aideyan U.O., Zaleski C G., Rodriguez M. M..Pediatric case of the day. Radiographics, May-June 1997:805-807

[6]. Erdem S, Küçükosmanoglu O, Salih O. K, Poyrazoglu H, Erdogan F, Tunali N, Özbarlas N. A case report: rhabdomyoma caused right ventricular outflow tract obstruction in an infant. Anadolu kardiyol derg, 2003; 3: 171-173

[7]. Marx GR, Moran MA. Cardiac Tumors. In: Allen HD, Gutgesell HP, Clark EB, Editors. Moss and Adams' heart disease in infant, children and adolescents. $6^{\text {th }}$ Edition. Philadelphia: Lippincott Williams and Wilkins; 2000: 1435-7

[8]. Bosi G, Lintermans JP, Pellegrino PA, Svaluto-Moreolo G, Vliers A. The natural history of cardiac rhabdomyoma with and without tuberous sclerosis. Acta Paediatr 1996 Aug; 85(8):928-31

[9]. Kalgutkar A, Pandit S, Pethe V M., Mondkar J.A., Fernandes A. Neonatal cardiac rhabdomyoma - a case report. Indian Pediatrics December $1998 ; 35 ; 12: 1228-30$ 
Figure 1: ash leaf spot on right flanks

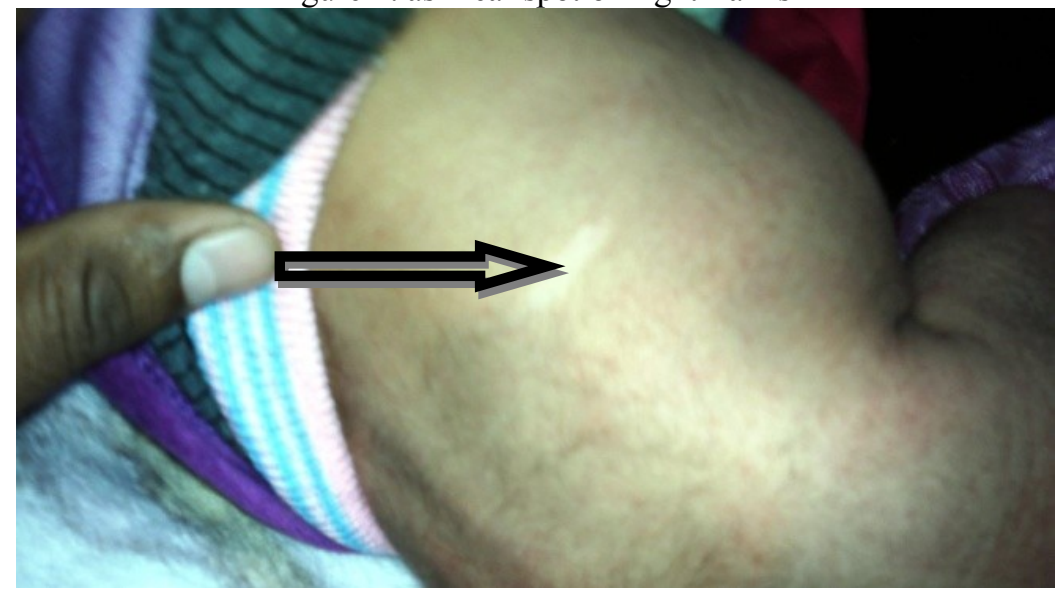

Figure 2: 2D ECHO suggestive of multiple cardiac tumors

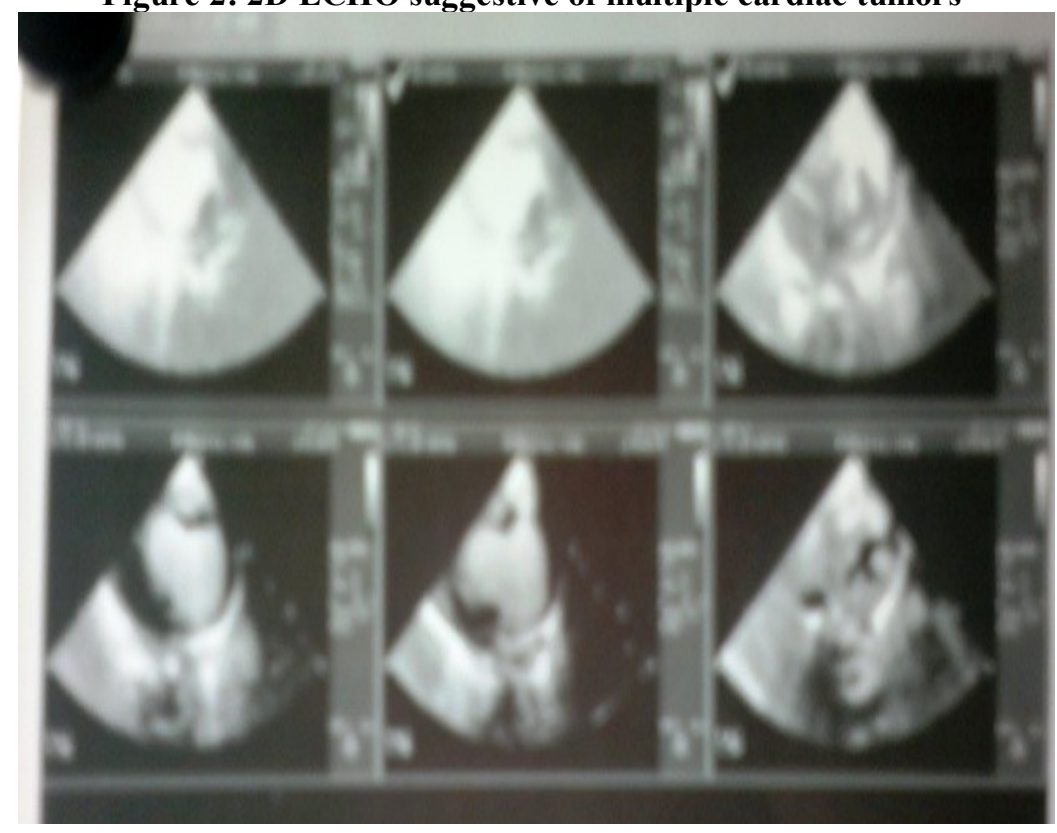

Figure 3: CT SCAN BRAIN suggestive of tuberous sclerosis

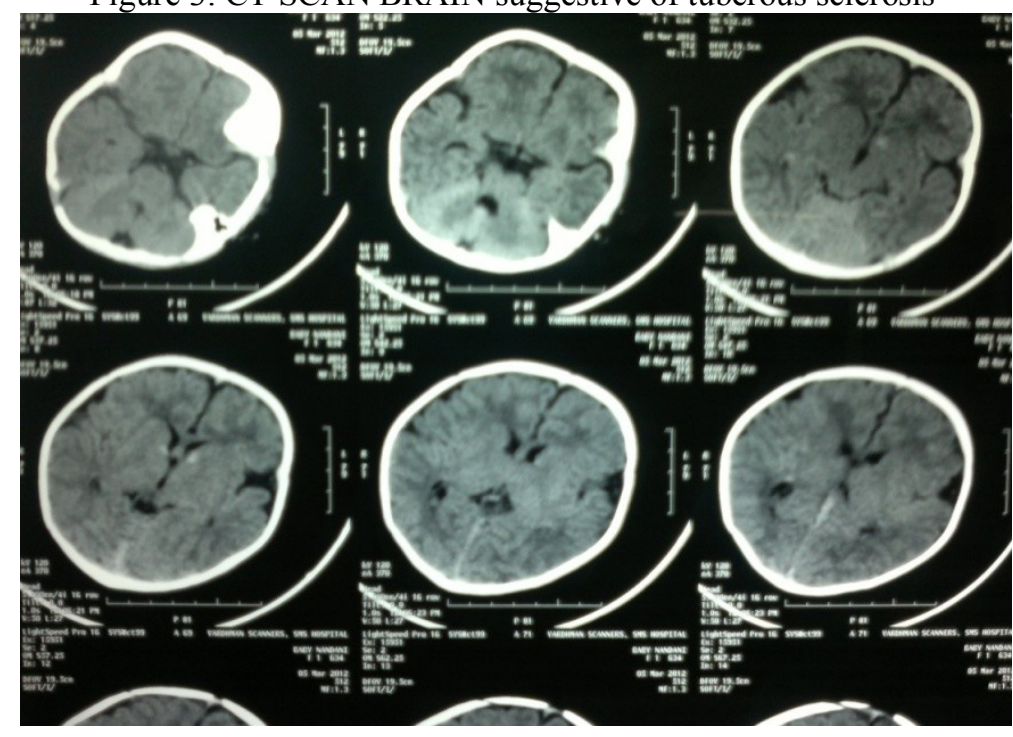

